\title{
THE RELATIONSHIP BETWEEN ALEXITHYMIA AND SUICIDE AMONG MOROCCAN PATIENTS WITH SUBSTANCE USE DISORDERS (SUD)
}

Karjouh K. ${ }^{1}$, Azzaoui F-Z. ${ }^{1}$, Ahami A. ${ }^{1}$, Boulbaroud S. ${ }^{2}$, Hami H. ${ }^{3}$

1. Unit of Cognitive and Behavioral Neuroscience and Applied Nutrition, Faculty of Science, Ibn Tofail University, Kenitra, Morocco.

2. Polydisciplinary Faculty, My. Slimane University, Beni Mellal, Morocco.

3. Laboratory of Genetics and Biometry, Faculty of Science, Ibn Tofail University, Kenitra, Morocco.

\begin{abstract}
Background and aims: To estimate the prevalence of alexithymia among drug addicted patients and to determine the relation between alexithymia and suicidal ideation and factors associated with suicidal ideation among drug addicted patients.
\end{abstract}

Objective: Suicidal incidence rates are known to be high in patients manifesting SUD. We attempt to characterize suicidal ideation and behaviours in patients with drug addiction in relation to alexithymia.

Materials and methods: A sample of 152 drug addicted patients $(77 \%$ Male and $23 \%$ F), who respond to sociodemographic questionnaire are recruited to this study. Alexithymia is measured by Toronto Alexithymia Scale-20 (TAS-20), suicidal ideation and behaviours are measured by Columbia-Suicide Severity Rating Scale (C-SSRS).

Results: Among substance-dependent patients $53 \%$ was considered as a group with alexithymia (Table 1).

Figure 1: Frequency of alexithymia

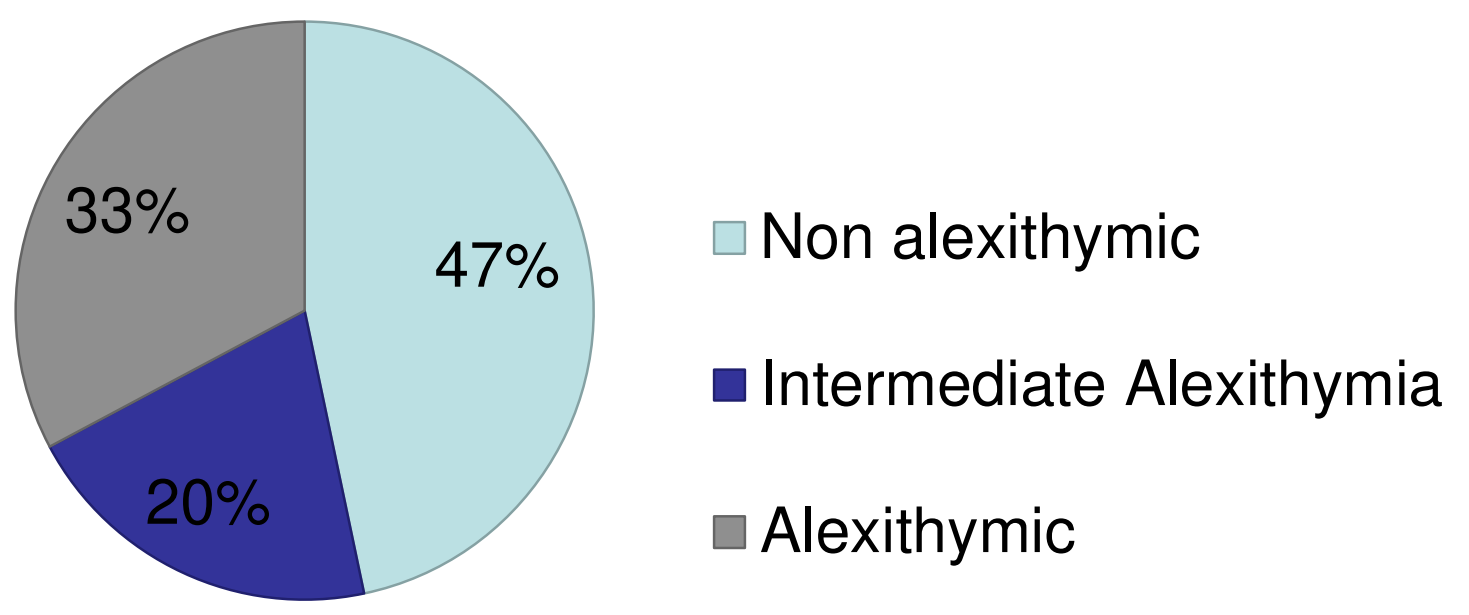

Table 1: Psychometric measures and clinical variables of patients with substance abuse

\begin{tabular}{|c|c|c|c|c|}
\hline & Alexithymic & $\begin{array}{c}\text { Non } \\
\text { Alexithymic }\end{array}$ & $\mathbf{t}$ & $p$ \\
\hline $\begin{array}{l}\text { Age } \\
(\text { mean } \pm S D)\end{array}$ & $26,23 \pm 10,039$ & $27,98 \pm 11,765$ & 3,578 & 0,059 \\
\hline $\begin{array}{l}\text { Age on onset } \\
\text { (mean } \pm S D)\end{array}$ & $14,88 \pm 3,459$ & $15,74 \pm 4,943$ & 10,191 & $0,002^{*}$ \\
\hline $\begin{array}{l}\text { Suicidal } \\
\text { Ideation } \\
\text { (meantSD) }\end{array}$ & $1,82 \pm 1,984$ & $1,03 \pm 1,607$ & 21,145 & $0,000^{*}$ \\
\hline $\begin{array}{l}\text { Suicidal } \\
\text { Behaviour } \\
\text { (meantSD) }\end{array}$ & $1,16 \pm 1,716$ & $0,57 \pm 1,339$ & 30,323 & $0,000^{*}$ \\
\hline
\end{tabular}

$\mathrm{t}=$ Student $\mathrm{t}$ test, $($ mean $\pm \mathrm{s} . \mathrm{d})=$ Mean \pm standard deviation, ${ }^{*} \mathrm{p}<0.01$

The groups differed significantly in terms of psychometric measures. TAS-20 subscales also differed significantly between groups (Table 1).

Age correlated significantly with age at onset in PASs abusers; and it were correlated with neither the severity of alexithymia nor the severity of suicidal ideations and behaviours, while there was a moderate negative correlation between age at onset and the severity of alexithymia. A significant correlation was found between TAS 20, its factors and C-SSRS (Table 2).

Table 2: Correlations of clinical scales in the patient group

\begin{tabular}{|l|c|c|c|c|c|}
\hline & Age & Age at onset & TAS-20 & Suicidal ideation & Suicidal Behavior \\
\hline Age & 1,0000 & & & & \\
\hline Age at onset & $\mathrm{p}=---$ & & & & \\
\hline & $\underline{2254}$ & 1,0000 & & & \\
\hline TAS-20 & $\mathrm{p}=, 000$ & $\mathrm{p}=---$ & & & \\
\hline &,- 0050 & $\underline{-1158}$ & 1,0000 & & \\
\hline Suicidal Ideation & $\mathrm{p}=, 915$ & $\underline{\mathrm{p}=, 014}$ & $\mathrm{p}=---$ & 1,0000 & \\
\hline &, 0449 &, 0589 & $\underline{2372}$ & $\mathrm{p}=---$ & 1,0000 \\
\hline Suicidal Behavior & $\mathrm{p}=, 344$ & $\mathrm{p}=, 215$ & $\underline{\mathrm{p}=, 000}$ & $\underline{2064}$ & $\mathrm{p}=---$ \\
\hline
\end{tabular}

Conclusion: SUD patients with intensive suicidal ideation and behaviours accompanied with alexithymia are characterized by the inability to communicate feelings. Therefore, suicidal ideation and behaviours may occur in those patients without expressed suicide message. Based upon the finding's, alexithymia may be a good predictor of suicidal ideation and behaviours for preventing suicidal attempts in patients with drug addiction.

\section{References :}

De Berardis D, Fornaro M, Orsolini L, Valchera A, Carano A, Vellante F, Perna G, Serafini G, Gonda X, Pompili M, Martinotti G and Di Giannantonio M (2017) Alexithymia and Suicide Risk in Psychiatric Disorders: A Mini-Review. Front. Psychiatry 8:148. doi: 10.3389/fpsyt.2017.00148

Hemming, L., Taylor, P., Haddock, G., Shaw, J., \& Pratt, D. (2019). A systematic review and meta-analysis of the association between alexithymia and suicide ideation and behaviour. Journal of Affective Disorders. doi:10.1016/j.jad.2019.05.013 . 